\title{
Foot and mouth disease in Zambia: Spatial and temporal distributions of outbreaks, assessment of clusters and implications for control
}

\begin{abstract}
Authors:
Yona Sinkala ${ }^{1,2}$

Martin Simuunza ${ }^{1}$

John B. Muma ${ }^{1}$

Dirk U. Pfeiffer ${ }^{3}$

Christopher J. Kasanga ${ }^{4}$

Aaron Mweene ${ }^{1}$

Affiliations:

${ }^{1}$ Department of Disease

Control, University of

Zambia, Zambia
\end{abstract}

${ }^{2}$ Ministry of Agriculture and Livestock, Zambia

${ }^{3}$ Department of Veterinary Clinical Sciences, Royal Veterinary College, United Kingdom

${ }^{4}$ Department of Veterinary Microbiology and Parasitology, Sokoine University of Agriculture,

Tanzania

Correspondence to: Yona Sinkala

Email:

yona.sinkala@sacids.org

Postal address:

PO Box 32379, Lusaka, Zambia

How to cite this article: Sinkala, Y., Simuunza, M. Muma, J.B., Pfeiffer, D.U., Kasanga, C.J. \& Mweene, A., 2014,' Foot and mouth disease in Zambia: Spatial and temporal distributions of outbreaks, assessment of clusters and implications for control', Onderstepoort Journal of Veterinary Research 81(2), Art. \#741 6 pages. http://dx.doi. org/10.4102/ojvr.v81i2.741
Zambia has been experiencing low livestock productivity as well as trade restrictions owing to the occurrence of foot and mouth disease (FMD), but little is known about the epidemiology of the disease in these endemic settings. The fundamental questions relate to the spatio-temporal distribution of FMD cases and what determines their occurrence. A retrospective review of FMD cases in Zambia from 1981 to 2012 was conducted using geographical information systems and the SaTScan software package. Information was collected from peer-reviewed journal articles, conference proceedings, laboratory reports, unpublished scientific reports and grey literature. A space-time permutation probability model using a varying time window of one year was used to scan for areas with high infection rates. The spatial scan statistic detected a significant purely spatial cluster around the Mbala-Isoka area between 2009 and 2012, with secondary clusters in Sesheke-Kazungula in 2007 and 2008, the Kafue flats in 2004 and 2005 and Livingstone in 2012. This study provides evidence of the existence of statistically significant FMD clusters and an increase in occurrence in Zambia between 2004 and 2012. The identified clusters agree with areas known to be at high risk of FMD. The FMD virus transmission dynamics and the heterogeneous variability in risk within these locations may need further investigation.

\section{Introduction}

Foot and mouth disease (FMD) is endemic in Zambia and several other African countries and impacts negatively on the livelihoods of the people (Perry \& Hedger 1984; Perry \& Stones 2007). FMD is the single most important economic animal disease affecting regional trade in livestock, wildlife and other agricultural products within the Southern African Development Community and Common Market for East and Southern Africa. Zambia, like many other African countries, is looking for ways to derive maximum benefit from trade in livestock and wildlife resources through prescribed international standards such as disease-free zones and the progressive control pathway. Many economists consider regional trade in the subregion as a vehicle for economic growth, poverty reduction and achievement of the much desired millennium development goals.

Since the first case in 1933, several outbreaks have occurred in Zambia and areas with a high FMD risk have been described (Chilonda et al. 1999; Mweene et al. 1996; Overby \& Zyambo 1983; Perry \& Hedger 1984; Zyambo 1975). These studies were all conducted more than two decades ago. However, the epidemiological pattern of FMD may not remain static in space and time owing to both its highly contagious nature (Radostits, Blood \& Gay 1994) and the behaviour of human populations. The most recent study (Chilonda et al. 1999) concluded that the epidemiology of FMD transmission in Zambia is not adequately understood. Since then several outbreaks have occurred within Zambia and the surrounding region, with an increased frequency observed since 2004 (Thobokwe et al. 2010; Thomson, Penrith \& Fosgate 2012). The reasons for the recent outbreaks in Zambia are not well known, but elsewhere in the region it is suspected to be as a result of the breakdown in the once effective control measures of the 1980s and 1990s. Therefore, the spatial aggregation of FMD cases needs to be assessed and updated to help design effective control measures.

The epidemiology of FMD in sub-Saharan Africa is further complicated by:

- the presence of reservoir African buffalo (Syncerus caffer) and several other host species

- the presence of six of the seven known FMD virus (FMDV) serotypes, of which the most notable are the Southern African Territory (SAT) serotypes

- mutations of the FMDV

- rampant wildlife and livestock movement (Vosloo et al. 1995)

Note: Proceedings of the 2 nd One Health Conference in Africa. Jointly organised by the Southern African Centre for Infectious Disease Surveillance and the Tanzania National Institute for Medical Research, held at the Snow Crest Hotel in Arusha, Tanzania from 16th to 19th April 2013: http://www.sacids.org/kms/frontend/index.php?m=119.

Copyright: (C) 2014. The Authors. Licensee: AOSIS OpenJournals. This work is licensed under the Creative Commons Attribution License. 


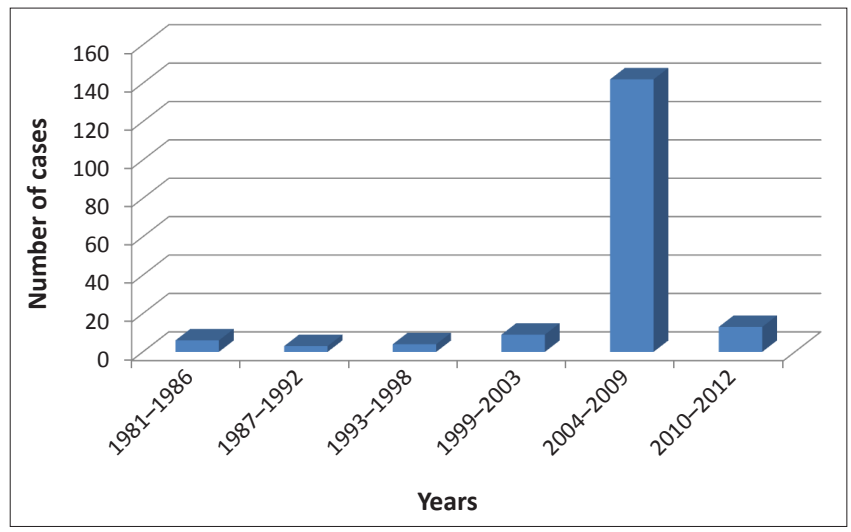

FIGURE 1: Graph of FMD cases from 1981-2012, showing an increase in the number of cases per five year period.

- the knowledge, attitude and perception of smallholder livestock farmers and traders about FMD (Perry \& Stones 2007).

Although the transmission of FMD from carriers (buffalo or cattle) to cattle is not fully understood, evidence exist that such transmission occurs only rarely (Condy \& Hedger 1974; Rweyemamu 1984). Despite several cohort studies regarding the trigger of this transmission, there have been no conclusive findings (Rweyemamu et al. 2008; Thomson et al. 1992; Vosloo, Bastos \& Boshoff 2005; Vosloo, Bastos \& Boshoff 2006). This knowledge gap creates challenges in understanding predictors of future outbreaks necessary for effective preventive control in endemic settings where buffalo and cattle co-exist. These cohort studies are expensive and it may be difficult to mimic what happens in nature in an experimental setup. In addition, findings regarding the epidemiology of FMD in a wildlife species in one ecological region may not be able to be extrapolated to other regions because of ecological and viral variability (Vosloo et al. 2009). Therefore, research is recommended to understand what factors could pertain to the epidemiology of the disease in potential high-risk areas.

The objectives if this study were (1) to investigate the spatial distribution of FMD in Zambia between 1981 and 2012, (2) to identify the significant FMD clusters and (3) to discuss them in relation to predisposing factors.

\section{Materials and method \\ Study area}

Zambia extends over $752000 \mathrm{~km}^{2}$ and has a population of 13.4 million, of which the majority $(61 \%)$ are concentrated in the rural areas (CSO 2010). The country has more grazing land than arable land. Most rural Zambian populations depend on livestock for their livelihood. Traditional farmers own $84 \%$ of the estimated $3.4 \mathrm{~m}$ cattle, $68 \%$ of the 450000 sheep, $97 \%$ of the $1 \mathrm{~m}$ goats and $90 \%$ of the $1.5 \mathrm{~m}$ pigs (Ministry of Livestock and Fisheries Development 2011). FMD is a notifiable disease of national economic importance in Zambia, which compels the government to assume the cost of control during an outbreak.

The disease is often under-reported and not all outbreaks that are sampled are analysed owing to poor sampling, storage and despatch techniques. FMD in Zambia has always been mild in indigenous cattle, often causing only transient paralysis (occult form of the disease) (Mweene et al. 1996; Zyambo 1975). Most traditional animals are not closely monitored except during ploughing periods.

\section{Data collection}

The study was a retrospective FMD case series. A case is defined as a clinical presentation of FMD-like lesions and confirmed by laboratory analysis. Because of the social economic status of cattle, FMD is reported only for this species in Zambia. There is a notable absence of records of FMD in pigs, sheep and goats, except for a passing reference to natural cases of FMD in pigs in 1935 and an outbreak in the Southern province in 1979 (Chilonda et al. 1999). Data on FMD cases recorded in Zambia between 1981 and 2012 were obtained from peer-reviewed journal articles, conference proceedings, reference laboratory reports, unpublished scientific reports and grey literature. The grey literature included records from the National Epidemiology Unit, the virology database of the Central Veterinary Research Laboratory, annual reports from the Ministry of Agriculture, FMD reports from the Animal Health Institute (Pirbright), the Onderstepoort Veterinary Institute and the Botswana Vaccine Institute. The case data included date of occurrence, location, number of cases, population at risk (where available), serotype involved, vaccination and vaccine used.

\section{Data management and geocoding}

The disease data consisted of 178 FMD-positive cases in 86 locations over the 31-year period. The cases were from villages and veterinary camps. A spatial coordinate system was used for geo-referencing the cases using the available smallest administrative units of village or veterinary camp (Figure 2). Two files were developed for use in SaTScan (free software developed by Kulldorff [2012]): a case file in spreadsheet format detailing location identification, number of cases and the date the cases were reported, and a geocoded file that contained location identification and the latitude and longitudes of the locations of cases. Both file types were saved as a space-delimited format. The coordinates for the identified clusters and the FMD cases were projected to the Universal Transverse Mercator (UTM) zone 35S World Geodetic System (WGS) 1984 and represented using ArcGIS version 10.1 (Environmental Systems Research Institute, Redlands, California). A topographic map of Zambia was used as a reference for relating cases and clusters to geographical features such as roads, national parks, rivers and international boundaries.

\section{Statistical analysis}

Spatial analysis can be used on disease outbreak data to describe geographical patterns of disease (e.g. clusters). Disease clusters can help in identifying common environmental factors or sources of exposure (Chhetri, Perez \& Thurmond 2010; Premashthira et al. 2011). The null hypothesis was that the number of infected villages or veterinary camps, their location and the time frame of 


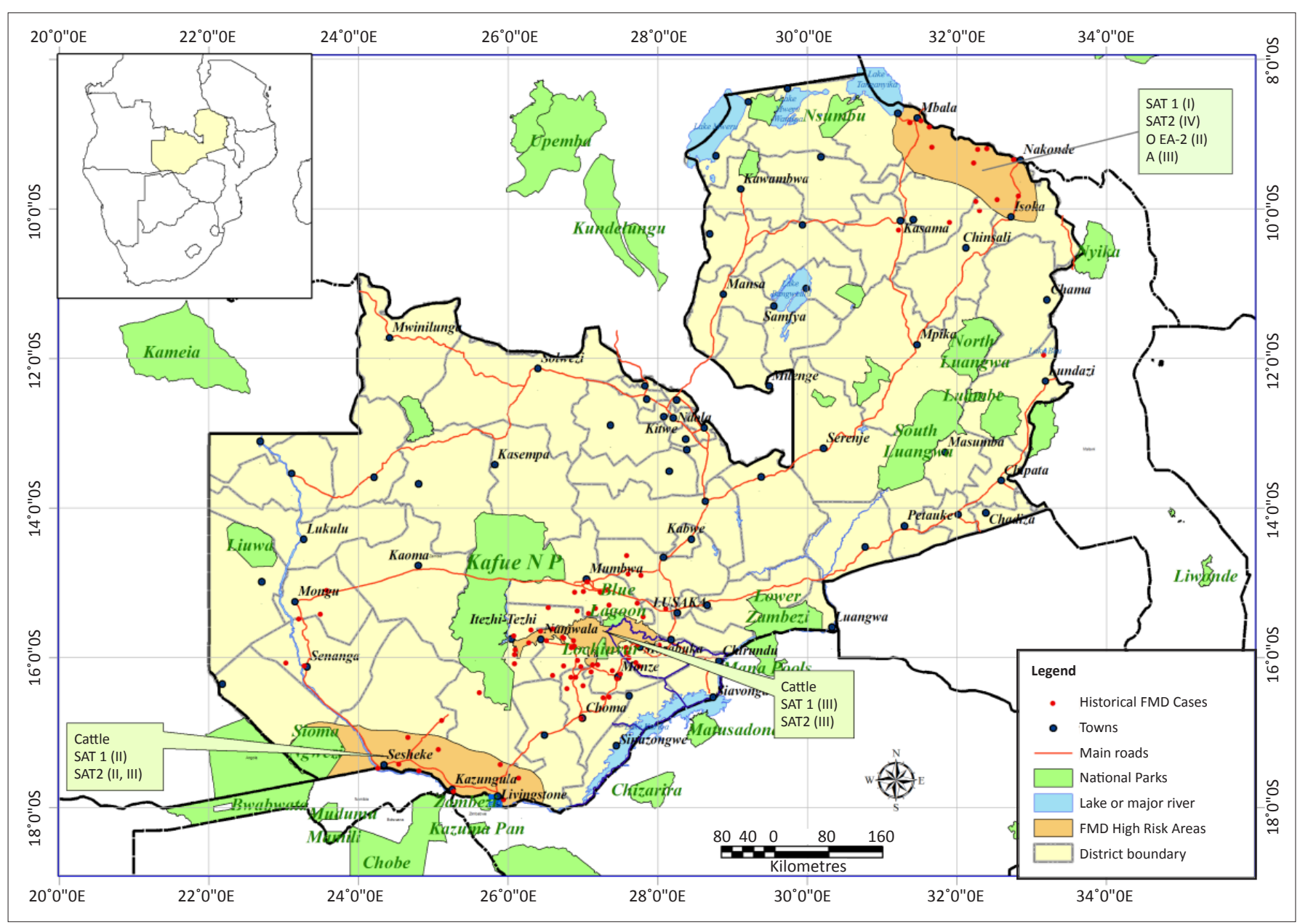

Note: The insert shows the relative location of Zambia in southern Africa.

FIGURE 2: Spatial distribution of cases of foot and mouth disease in Zambia (according to serotype and topotype) within the three high-risk areas.

infection were similar. Therefore, the disease likelihood ratio was expected to be constant over the whole territory and time frame under analysis. The analysis included the hypothesis that the number of cases reported within a certain geographical area was higher than that observed outside that area during the epidemic and was assessed by a purely spatial test. Clustering was also assessed across different time intervals by the space-time test.

A hypothesis could then be generated to understand disease epicentres - how the disease is sustained over time in endemic situations and the variation in risk within a perceived highrisk area. Spatial scan statistics (Kulldorff \& Nagarwalla 1995) are frequently used for geographical disease cluster detection and cluster evaluation in disease surveillance. The advantages of using the SaTScan program are that it can adjust for confounding variables, resolves pre-selection bias as it searches for clusters without specifying their size or location, gives a single $p$-value as the likelihood ratio-based test takes account of multiple testing, and can be applied to a whole region to detect clusters (Kulldorff et al. 2005).

The SaTScan software scans for temporal, spatial and spatial-temporal clusters. Briefly, it selects scanning windows of continuously varying sizes over a spatial study area. For each location and size of the scanning window, the alternative hypothesis is that there is an elevated rate within the window compared with outside. The most likely cluster was determined by maximising a likelihood function over all the zones. Once the window with the greatest likelihood ratio statistic has been identified, the sampling distribution of the likelihood ratio is evaluated using a Monte Carlo test (9999 repetitions). A likelihood ratio was created by dividing the maximum likelihood value by another likelihood value based on the null hypothesis. We used space-time retrospective analysis using the space-time permutation probability model, scanning for areas with high rates. A oneyear unit was used as case data are available only per year.

\section{Results}

The space-time test identified four significant clusters in different time periods (years) and the null hypothesis was subsequently rejected. The most likely cluster was located in the Kasama district $(n=10)$, with a radius of $167 \mathrm{~km}$, between 2009 and 2012. The likely secondary clusters were located in Senanga ( $n=13$ ), with a radius of $279 \mathrm{~km}$, between 2007 and 2008, Itezhitezhi $(n=48)$, with a radius of $137 \mathrm{~km}$, between 2004 and 2005, and Katapazi (Livingstone) $(n=3)$, with a radius of $39 \mathrm{~km}$ in 2012 (Figure 1, Figure 2, Figure 3 and Table 1). The study did not control for covariates 


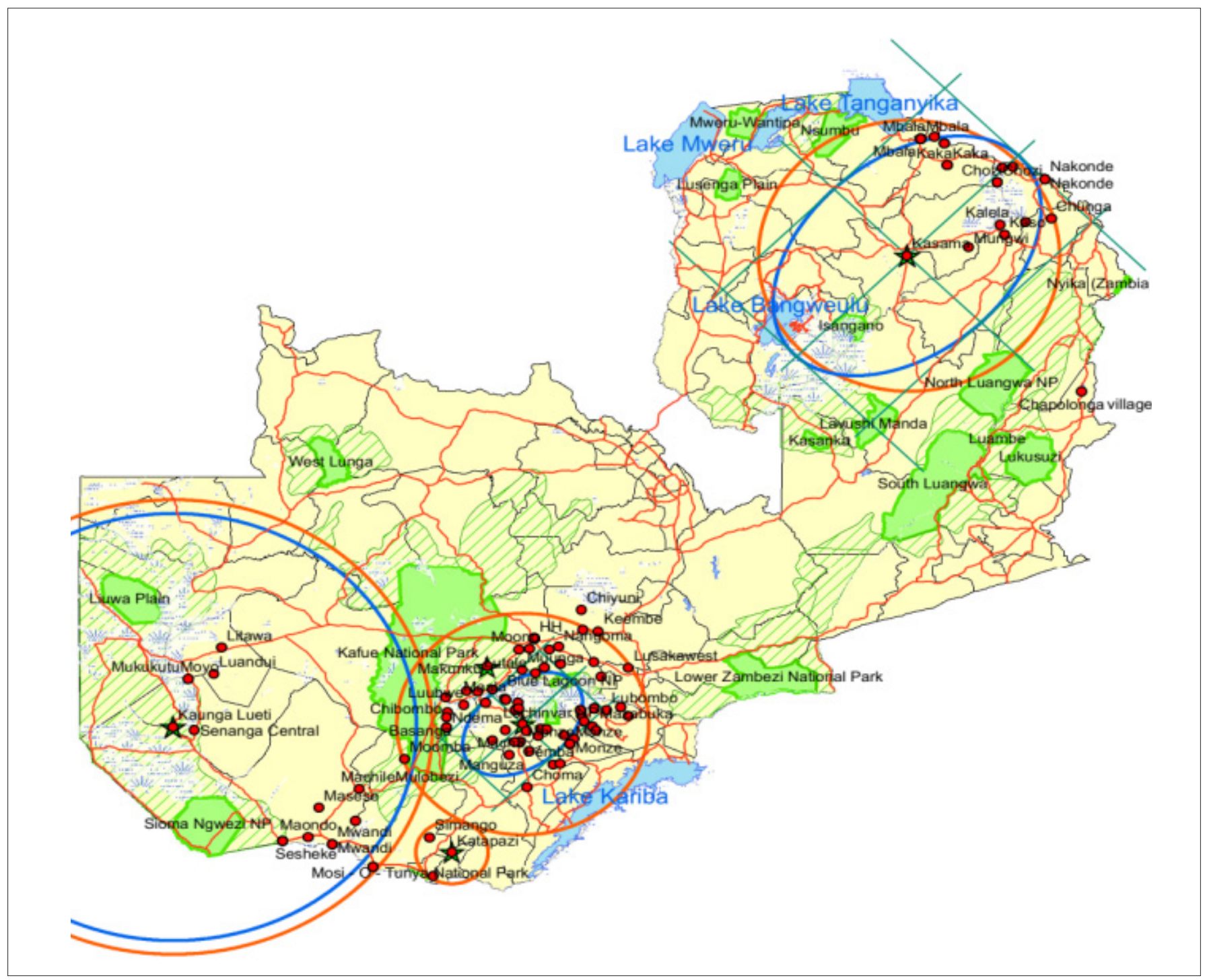

Note: The orange circles indicate the circular clusters.

FIGURE 3: Clusters of foot and mouth disease in Zambia as identified by SaTScan.

TABLE 1: Space-time foot and mouth disease clusters in Zambia as identified using the space-time permutation probability model.

\begin{tabular}{|c|c|c|c|c|}
\hline Cluster & Primary (C1) & Secondary (C2) & Secondary (C3) & Secondary (C4) \\
\hline Location & $\begin{array}{l}\text { Kasama, Kalela, Kaso, Kaka, Chozi, } \\
\text { Musemazi, Mwamba, Mbala, } \\
\text { Kawimbe, Ntatumbila }\end{array}$ & $\begin{array}{l}\text { Makunku, Banamwanze, Baanga, Babizhi, } \\
\text { Muunga, Lutale, Maala, Baambwe, } \\
\text { Namwala, Moono, Nalubanda, Luubwe, } \\
\text { Kantengwa, Itezhitezhi, Hakainde } \\
\text { Hichilema, Mumbwa, Muchabi, } \\
\text { Mumbwa Central, Namusonde, Katantila, } \\
\text { Kabulamwanda, Myooye, Chibombo, } \\
\text { Keezwa, Chitongo, Nangoma, Ndema, } \\
\text { Basanga, Basanga village, Chisoba farm, } \\
\text { Nakamboma, Muchila, Bweengwa, } \\
\text { Simaubi, Mapanza, Nakansangwe, } \\
\text { Hamangaba, Macha, Keembe ranch, } \\
\text { Kalambabakali, } \\
\text { Manguza, Mwanachingwala, } \\
\text { Mukulaikwa, Nteme, Shibuyunji, Chiyuni }\end{array}$ & $\begin{array}{l}\text { KaungaLueti, Senanga Central, } \\
\text { Moyo, Luandui, Litawa, Sesheke, } \\
\text { Kazungula, Moomba, Masese, } \\
\text { Maondo, Mulobezi, Mwandi, } \\
\text { Sakolonga/Magumwi }\end{array}$ & $\begin{array}{l}\text { Katapazi, Simango, } \\
\text { Mukuni }\end{array}$ \\
\hline Coordinates & $10.2850 \mathrm{~S}, 31.2245 \mathrm{E}$ & $15.3310 S, 26.5414 \mathrm{E}$ & $16.0730 \mathrm{~S}, 23.0332 \mathrm{E}$ & $17.6110 S, 26.1437 \mathrm{E}$ \\
\hline Radius (kilometres) & 166.74 & 136.61 & 279.41 & 38.85 \\
\hline Time frame & $\begin{array}{l}01 \text { January } 2009- \\
31 \text { December } 2012\end{array}$ & $\begin{array}{l}01 \text { January } 2004- \\
31 \text { December } 2005\end{array}$ & $\begin{array}{l}01 \text { January } 2007- \\
31 \text { December } 2008\end{array}$ & $\begin{array}{l}01 \text { January } 2012- \\
31 \text { December } 2012\end{array}$ \\
\hline Number of observations & 266 & 1698 & 318 & 52 \\
\hline Observed/Expected & 5.93 & 1.60 & 4.52 & 43.31 \\
\hline LLR/Test statistic & 258.93 & 240.34 & 240.56 & 145.50 \\
\hline$p$-value & $<0.001$ & $<0.001$ & $<0.001$ & $<0.001$ \\
\hline
\end{tabular}

Note: The space-time permutation probability model with a 1-year unit was used to scan for areas with high infection rates. LLR, likelihood ratio. 
or confounders but used molecular epidemiology reference laboratory reports on the likely source of the outbreaks to discuss potential factors.

\section{Discussion}

The results demonstrate the spatial distribution of FMD in Zambia. Four significant FMD clusters were indentified, including two distinct clusters within the lower Zambezi basin (Figure 3). Although based on geo-referenced and case report data, this report should not be construed as an evaluation of the FMD epidemics that occurred between 1981 and 2012; rather, it is intended as a hypothetical (yet realistic) scenario that facilitates the retrospective exploration and generation of hypotheses on epidemic spread. The findings are limited to the data set investigated and do not factor in the level of under-reporting, unconfirmed samples, livestock or wildlife densities and serotype variations. Therefore, the findings should best be regarded as evidence of associations that may support specific hypotheses.

The data are compatible with the assertion that FMD in Zambia shows two epidemiological patterns. One is related to serotypes O, SAT 1 and SAT 2 being maintained and spread by livestock movement along the border with Tanzania (Perry \& Hedger 1984). This is where the primary cluster was located (around Kasama) between 2009 and 2012, with most index cases being in the Mbala district.

The second is the SAT 1 and SAT 2 serotypes in the Kafue flats and Zambezi basin being maintained and spread by both African buffalo and domestic livestock movement. The SAT viruses may also become established in cattle, leading to cyclic incidences as naïve populations increase if the basic reproduction number is not reduced to less than 1 (Rweyemamu et al. 2008).

In the Kafue flats, Itezhitezhi was identified as the centre of the 2004-2005 cluster, with the index case in Katengwa, Namwala district. These two areas are within the Kafue flats, where more than 600000 cattle compete with approximately 9000 buffalo (1000 from the Lochnivar National Park; 8000 from the Kafue National Park) for grazing and water annually (Zambia Wildlife Authority 2007; Chilonda et al. 1999). The high contact rates between cattle and wildlife (buffalo) in the dry season is believed to be the source of most of the FMD outbreaks. Historically, outbreak index cases in this area have generally been identified on the fringes of the Lochnivar National Park in Namwala, Mazabuka or Monze (Overby \& Zyambo 1983; Perry \& Hedger 1984; Zyambo 1975). This primary source of exposure, together with secondary movement of infected cattle, may be the major reason for the spatial clustering observed (Zyambo 1975). In the Zambezi basin, two distinct clusters around Senanga (2007-2008) and Livingstone (2012) have been identified. Whilst the centre of the cluster was located around the Senanga district, the index case was in Mwandi (Sesheke) from where infections spread to Kazungula, Senanga, Mongu and Kalabo. This outbreak was associated with serotype SAT 2 and two plausible sources of origin have emerged. One source is attributed to buffalo, as the area lies on a buffalo migratory route between the Chobe National Park in Botswana and the Sichifulo game management area in Zambia. This is supported by molecular evidence that associated the virus to the buffalo strain that was isolated from Chobe National Park earlier (FAO_ WRLFMD 2012a). The second source is attributed to the movement of cattle from neighbouring Namibia (Bastos et al. 2003; Mweene et al. 1996) and molecular evidence shows an association between the outbreak virus and the one isolated from a Namibian outbreak in cattle earlier (FAO_WRLFMD 2012a). The Livingstone Katapazi cluster of 2012 was associated with serotype SAT 1 and showed no relationship with any other virus isolated in the area (FAO_WRLFMD 2012b), which supports the suspicion that it may have come from contact with buffalo that were spotted in the area. In our view, the two Lower Zambezi clusters, although close to each other, should be considered separately as the sources of risk are most likely different and considerations may have to be made in disease control approaches.

Data are available only for certain localities and underreporting is likely as diseases such as FMD are known to spread spatially unless adjacent areas are devoid of susceptible animals. Under-reporting and the aggregation of cases to veterinary camps or districts may negatively impact the ability to determine the exact spatial location of the outbreak accurately, particularly so in small clusters $\left(<800 \mathrm{~km}^{2}\right)$ (Jones \& Kulldorff 2012). Jones and Kulldorff (2012) also report that the likelihood of spatially overestimating outbreaks by including geographical areas outside the actual disease cluster increases with aggregated data. The creation of windows that may include areas that have not reported FMD (e.g. west and south of the primary cluster) is one of the inherent limitations of SaTScan (Jones \& Kulldorff 2012; Rivas et al. 2006).

Our study supports the alternative hypothesis that there is an elevated risk for those areas located within the identified clusters compared with those beyond. The reasons for the difference in risk for the areas located within and beyond the clusters require further investigation. The factor associated with FMD clustering may be either within or beyond the location where the disease is observed (Rivas et al. 2006). For example, in the case of market-driven spread, the cluster location may be different from the market. FMD outbreaks in Zambia have long been associated with livestock movement along trade routes (Bastos et al. 2003; Perry \& Hedger 1984; Zyambo 1975). These movements are largely driven by incentives related to differences in price of livestock and therefore the epidemiology of FMD cannot be separated from the economics of livestock marketing (Rushton 2008). Understanding the behaviour of small-scale farmers and livestock traders alike may provide clues to disentangling the endemicity (Perry \& Rich 2007) of the disease. Therefore, the role of people networks in the epidemiology of FMD may need to be investigated further.

\section{Implications for control measures}

The identified clusters may be taken into consideration when formulating new disease control strategies, especially in the context of the planned disease-free zones (Republic of 
Zambia 2011). As the risk is not static and may change with the changing disease dynamics, more targeted surveillance within and beyond the identified clusters is recommended. The Kafue flats and the two Zambezi basin clusters lie within the Zambezi Kavango Transfrontier Conservation Area (KAZA-TFCA 2013), where free roaming of wildlife (buffalo) is being promoted without regard for the FMD risks. It is therefore necessary to profile FMD clusters with a view to influence control measures if benefits are to be realised from livestock trade.

\section{Conclusion}

The FMD clusters may not be stated depending on exposing factors and therefore evaluation is periodically relevant in these endemic settings. The exposure to FMDV in the identified clusters may be a result of epidemiological, ecological and sociological processes. Understanding these processes may lead to innovative solutions that should be considered in the FMD control pathway for Zambia and southern Africa. Our study therefore provides a basis for risk-based surveillance and further investigations into risk determinants within the identified clusters.

\section{Acknowledgements}

This work was supported by a grant (WT087546MA) from the Wellcome Trust to the Southern Africa Centre for Infectious Disease Surveillance (SACIDS). The authors are grateful to the Veterinary Department of the Zambian Ministry of Agriculture and Livestock for permission to use the FMD outbreak data and the relevant documents referenced in this study.

\section{Competing interests}

The authors declare that they have no financial or personal relationship(s) that may have inappropriately influenced them in writing this article.

\section{Authors' contributions}

Y.S. (University of Zambia and Ministry of Agriculture and Livestock, Zambia) collected the data, conducted the analysis and prepared the manuscript. M.S. (University of Zambia), J.B.M. (University of Zambia) and C.J.K. (Sokoine University of Agriculture) edited the manuscript. A.M. (University of Zambia) and D.U.P. (Royal Veterinary College) approved and proofread the work.

\section{References}

Bastos, A.D., Haydon, D.T., Sangare, O., Boshoff, C.I., Edrich, J.L. \& Thomson, G.R., 2003, 'The implications of virus diversity within the SAT 2 serotype for control of foot-and-mouth disease in sub-Saharan Africa', Journal of General Virology 84, 1595-606. http://dx.doi.org/10.1099/vir.0.18859-0

Chhetri, B.K., Perez, A.M. \& Thurmond, M.C., 2010, 'Factors associated with spatial clustering of foot-and-mouth disease in Nepal', Tropical Animal Health and Production 42, 1441-1449. http://dx.doi.org/10.1007/s11250-010-9573-7

Chilonda, P., Woodford, J.D., Ahmadu, B., Samui, K.L., Syakalima, M. \& Mlangwa, J.E., 1999, 'Foot and mouth disease in Zambia: A review of the aetiology and epidemiology and recommendations for possible control', Revue Scientifique et Technique (International Office of Epizootics) 18, 585-592.

Condy, J.B. \& Hedger, R.S., 1974, 'The survival of foot and mouth disease virus in African Buffalo with non-transference of infection to domestic cattle', Research in Veterinary Science 16, 182-185.
CSO, 2010, Zambia 2010 Census of Population and Housing, Central Statistics Office, Lusaka, viewed 22 October 2012, from http://unstats.un.org/unsd/demographic/ sources/census/2010_phc/Zambia/PreliminaryReport.pdf

FAO_WRLFMD, 2012a, Molecular epidemiology reports for Zambia, FAO World Reference Laboratory for FMD, Pirbright, viewed 02 April 2013, from http://www. wrlfmd.org/fmd genotyping/africa/zam.htm

FAO_WRLFMD, 2012b, OIE/FAO Reference Laboratory Contract Report OctoberDecember 2012, FAO World Reference Laboratory for FMD, Pirbright, viewed 02 April 2013, from http://www.wrlfmd.org/ref_labs/ref_lab_reports/OIE-FAO\%20 FMD\%20Ref\%20Lab\%20Report\%20Oct-Dec\%202012.pdf

Jones, S. \& Kulldorff, M., 2012, 'Influence of spatial resolution on space-time disease cluster detection', PLOS ONE 7(10), e48036 http://dx.doi.org/10.1371/journal. pone. 0048036

KAZA-TFCA, 2013, Kavango Zambezi Trans-frontier Conservation Area, KAZA-TFCA, Kasane, viewed 09 April 2013, from http://www.kavangozambezi.org/the_map.php

Kulldorff, M., Heffernan, R., Hartman, J., Assuncao, R. \& Mostashari, F., 2005, 'A spacetime permutation scan statistic for disease outbreak detection', PLoS Medicine 2(3), e59. http://dx.doi.org/10.1371/journal.pmed.0020059

Kulldorff, M. \& Nagarwalla, N., 1995, 'Spatial disease clusters: Detection and inference', Statistics in Medicine 14, 799-810. http://dx.doi.org/10.1002/sim.4780140809

Ministry of Livestock and Fisheries Development, 2011, Annual report: In Services, V. Lusaka, Zambia.

Mweene, A.S., Pandey, G.S., Sinyangwe, P., Nambota, A., Samui, K. \& Kida, H., 1996, 'Viral diseases of livestock in Zambia', Japanese Journal of Veterinary Research 44, 89-105.

Overby, E. \& Zyambo, G.C.N., 1983, 'Foot and mouth disease outbreaks in Zambia', Revue Scientifique et Technique (International Office of Epizootics) 2, 189-197.

Perry, B. \& Stones, K., 2007, 'Poverty reduction through animal health', Science 315, 333-334. http://dx.doi.org/10.1126/science.1138614

Perry, B.D. \& Hedger, R.S., 1984, 'History and epidemiology of foot-and-mouth disease in Zambia: A review', Tropical Animal Health and Production 16, 107-114. http:// dx.doi.org/10.1007/BF02239854

Perry, B.D. \& Rich, K.M., 2007, 'Poverty impacts of foot-and-mouth disease and the poverty reduction implications of its control', Veterinary Record 160, 238-241. http://dx.doi.org/10.1136/vr.160.7.238

Radostits, O.M., Blood, D.C., Gay, C.C. (eds.), 1994, Foot-and-mouth disease (FMD, Aphthous fever). Veterinary Medicine: A Textbook of the Diseases of Cattle, Sheep, Pigs, Goats and Horses, pp 965-974, W.B. Saunders Company Ltd., London..

Republic of Zambia, 2011, Sixth National Development Plan for Zambia 2011-2015, Ministry of Finance and National Planning, Lusaka, Zambia.

Rivas, A.L., Kunsberg, B., Chowell, G., Smith, S.D., Hyman, J.M. \& Schwager, S.J., 2006, 'Human-mediated foot-and-mouth disease epidemic dispersal: Disease and vector
clusters', Journal of Veterinary Medicine 53,1-10. http://dx.doi.org/10.1111/ j.1439-0450.2006.00904.x

Rushton, J., 2008, 'Economic aspects of foot and mouth disease in Bolivia', Revue Scientifique et Technique (International Office of Epizootics) 27, 759-769.

Rweyemamu, M., Roeder, P., Mackay, D., Sumption, K., Brownlie, J., Leforban, Y. et al., 2008, 'Epidemiological patterns of foot-and-mouth disease worldwide' Transboundary and Emerging Diseases 55, 57-72. http://dx.doi.org/10.1111/ j.1865-1682.2007.01013.x

Rweyemamu, M. M., 1984, 'Foot and mouth disease control strategies in Africa', Preventive Veterinary Medicine 2, 329-340. http://dx.doi.org/10.1016/01675877(84)90076-X

Premashthira, S., Salman, M.D., Hill, A.E., Reich, R.M. \& Wagner, B.A., 2011 'Epidemiological simulation modeling and spatial analysis for foot-and-mouth disease control strategies: A comprehensive review', Animal Health Research Reviews 12, 225-234. http://dx.doi.org/10.1017/S146625231100017X

Thobokwe, G., Matlho, O.G., Fana, E.M. \& S, D., 2010, Resurgence of foot and mouth disease in the Southern Africa Development Community (SADC) region: Challenges to the Control strategies, Farm Inn, Republic of South Africa.

Thomson, G.R., Penrith, M.-L. \& Fosgate, G., 2012, 'Technical challenges associated with the eradication of TADs in southern Africa with special reference to FMD, Reconcilling Livestock Health and Wildlife Conservation goals in Southern Africa: Strategies for Sustainable Economic Development, Joint SADC/AHEAD Workshop, Phakalane Golf Estates, Gaborone, November 2012, pp. 1-6.

Thomson, G.R., Vosloo, W., Esterhuysen, J.J. \& Bengis, R.G., 1992, 'Maintenance of foot and mouth disease viruses in buffalo (Syncerus caffer Sparrman, 1779) in southern Africa', Revue Scientifique et Technique (International Office of Epizootics) 11, 10971107.

Vosloo, W., Bastos, A.D. \& Boshoff, C.I., 2005, 'Retrospective genetic analysis of SAT-1 type foot and mouth disease outbreaks in southern Africa', Archives of Virology 151 285-298. http://dx.doi.org/10.1007/s00705-005-0629-3

Vosloo, W., Bastos, A.D. \& Boshoff, C.I., 2006, 'Retrospective genetic analysis of SAT1 type foot-and-mouth disease outbreaks in southern Africa', Archives of Virology 151, 285-298. http://dx.doi.org/10.1007/s00705-005-0629-3

Vosloo, W., Kirkbride, E., Bengis, R.G., Keet, D.F. \& Thomson, G.R., 1995, 'Genome variation in the SAT types of foot-and-mouth disease viruses prevalent in buffalo (Syncerus caffer) in the Kruger National Park and other regions of southern Africa, 1986-93', Epidemiology and Infection 114, 203-218. http://dx.doi.org/10.1017/ S0950268800052055

Vosloo, W., Thompson, P.N., Botha, B., Bengis, R.G. \& Thomson, G.R., 2009, 'Longitudinal study to investigate the role of impala (Aepyceros melampus) in foot-and-mouth study to investigate the role of impala (Aepyceros melampus) in foot-and-mouth Emerging Diseases 56, 18-30. http://dx.doi.org/10.1111/j.1865-1682.2008.01059.x
Emeras

Zambia Wildlife Authority, 2007, Annual report, Zambia Wildlife Authority, Lusaka, Zambia.

Zyambo, G.C.N., 1975, 'Foot and mouth disease outbreaks in Zambia', Bulletin - Office International des Épizooties 83, 19-25. 